\title{
Gold nanoparticles for mercury determination in environmental water and vegetable samples
}

\author{
K. Kiran
}

Received: 22 May 2014/ Accepted: 3 June 2014/Published online: 27 June 2014

(C) The Author(s) 2014. This article is published with open access at Springerlink.com

\begin{abstract}
Gold nanoparticles (AuNPs) capped with 2-mercapto succinic acid (MSA) were successfully applied for the determination of mercury in various water samples up to nanolevels without any interference. Alumina-coated MSA-capped AuNPs easily remove mercury species present in various samples. The absorbance spectrum was obtained at $547 \mathrm{~nm}$. Other parameters like effect of $\mathrm{pH}$, reagent concentration, interferences were studied. This method is simple, sensitive and successfully applied for the determination of mercury species in various water, soil and plant residues collected from different industrial areas.
\end{abstract}

Keywords Gold nanoparticles · 2-Mercapto succinic acid $\cdot$ Activated alumina $\cdot$ Environmental samples

\section{Introduction}

Nowadays, nanometer-sized gold nanoparticles (AuNPs) for sample extraction in chemical analysis are gaining research interest. Compared with micrometer-sized particles used for solid-phase extraction (SPE), NPs offer a significantly higher surface area-to-volume ratio that promises much greater extraction capacity and efficiency. Another advantage of NPs is that NPs' surface functionality can be easily modified to achieve selective sample extraction or cell collection. A simple, rapid, sensitive and field-portable colorimetric technique for the determination of $\mathrm{Cr}(\mathrm{III})$ in aqueous solution based on an aggregation-

K. Kiran $(\bowtie)$

Department of Environmental Sciences, Sri Venkateswara

University, Tirupati 517502, AP, India

e-mail: kamatamkiran77@gmail.com induced color transition of AuNPs has been developed (Zhao et al. 2012). A simple and sensitive non-destructive method for the determination of the total concentration of dithiocarbamate fungicides (DTCs) in real samples was developed. The proposed method combines for the first time the benefits of an extraction method for sample cleanup and preconcentration with a sensitive colorimetric assay based on gold nanoparticle probes (Giannoulis et al. 2014). Bio-inspired colorimetric sensing systems have been developed to detect $\mathrm{Hg}^{2+}$ and $\mathrm{Pb}^{2+}$, and other cations, down to nmol $\left.\mathrm{L}^{-1}\right)$ concentrations.(Knecht and Sethi 2009). A novel method for selective determination of $\mathrm{Cr}(\mathrm{III})$ and $\mathrm{Cr}(\mathrm{VI})$ in environmental water samples was developed based on target-induced fluorescence quenching of glutathione-stabilized gold nanoclusters (GSH-Au NCs) (Zhang et al. 2013). A new type of alumina-coated magnetite nanoparticles $\left(\mathrm{Fe}_{3} \mathrm{O}_{4} / \mathrm{Al}_{2} \mathrm{O}_{3} \mathrm{NPs}\right)$ modified by the surfactant sodium dodecyl sulfate (SDS) has been successfully synthesized and applied for extraction of trimethoprim (TMP) from environmental water samples based on mixed hemimicelles' solid-phase extraction (MHSPE) (Sun et al. 2009). An efficient ligand-assisted phase transfer method has been developed to transfer AuNPs $(d=5-25 \mathrm{~nm})$ from an aqueous solution to $n$ hexane (Li et al. 2013).

A novel visual method for rapid assay of organophosphorus pesticides has been developed ( $\mathrm{Li}$ et al. 2011). A novel colorimetric method was developed for ultrasensitive detection of heparin based on self-assembly of AuNPs onto the surface of graphene oxide (GO). Polycationic protamine was used as a medium for inducing the selfassembly of citrate-capped AuNPs on GO through electrostatic interaction, resulting in a shift in the surface plasmon resonance (SPR) absorption of AuNPs and exhibiting a blue color (Fu et al. 2012). 
A colorimetric method was developed for determination of mercury ions $\left(\mathrm{Hg}^{2+}\right)$ and silver ions $\left(\mathrm{Ag}^{+}\right)$based on stabilization of AuNPs by redox formed metal coating in the presence of ascorbic acid (AA) (Lou et al. 2011). A rapid and homogeneous method for the highly selective detection of $\mathrm{Hg}^{2+}$ and $\mathrm{Ag}^{+}$using Tween 20-modified AuNPs was developed (Lin et al. 2010). Silver (Ag) and gold $\mathrm{Au}$ ) nanoparticles impregnated in nylon membrane filters have been proposed as a new solid phase for preconcentration of mercury from natural waters (Panichev et al. 2014).

An analytical method using silica-supported silver nanoparticles as a novel sorbent for the enrichment and determination of inorganic mercury $(\mathrm{iHg})$ in surface water samples has been developed (Yordanova et al. 2014). A simple method for the determination of ultra-trace amounts of inorganic mercury (iHg) and methylmercury $(\mathrm{MeHg})$ in waters and fish tissues was developed using a micro-column filled with polyaniline (PANI) coupled online to flow injection-chemical vapor generation-inductively coupled plasma mass spectrometry (FI-CVG-ICPMS) system (Krishna et al. 2010). A reagent-free fully automated flow injection analysis (FIA) system coupled to atomic fluorescence spectrometry (AFS) for mercury (Hg) quantification is reported, using active nano-structured gold collectors for direct preconcentration of dissolved mercury species from natural waters (Zierhut et al. 2010). A fully automated online ultraviolet (UV) digestion method for subsequent mercury $(\mathrm{Hg})$ quantification in humic matter containing river waters is reported. The newly developed flow injection analysis system (FIAS) consists basically of a UV lamp, a meander-form quartz glass reaction tube for online irradiation of the sample, and a nanogold collector for preconcentration of dissolved mercury species (Leopold et al. 2012).

In recent years, an increasing the number of works focused on the development of novel nanoparticle-based sensors for mercury detection, mainly motivated by the need of low-cost portable devices capable of giving fast and reliable analytical response, thus contributing to the analytical decentralization. Methodologies employing colorimetric, fluorometric, magnetic, and electrochemical output signals allowed reaching detection limits within the pM and nM ranges. Most of these developments proved their suitability in detecting and quantifying mercury (II) ions in synthetic solutions or spiked water samples. However, the state of art in these technologies is still behind the standard methods of mercury quantification, such as cold vapor atomic absorption spectrometry and inductively coupled plasma techniques, in terms of reliability and sensitivity. This is mainly because the response of nanoparticle-based sensors is highly affected by the sample matrix. The developed analytical nanosystems may fail in real samples because of the negative incidence of the ionic strength and the presence of exchangeable ligands.

The development of rapid, specific, cost-effective, and robust tools in monitoring $\mathrm{Hg}^{2+}$ levels in both environmental and biological samples is of utmost importance due to the severe mercury toxicity to humans. Bio-inspired colorimetric sensing systems have been developed to detect $\mathrm{Hg}^{2+}$ and $\mathrm{Pb}^{2+}$, and other cations, down to $\left.\mathrm{nmol} \mathrm{L}^{-1}\right)$ concentrations. The benefits of these systems, which are reviewed herein, include cost-effective production, facile usage, and a visual color change for the detection method (Knecht and Sethi 2009). Monitoring the levels of potentially toxic metal (PTM) ions, e.g., $\mathrm{Hg}, \mathrm{Pb}, \mathrm{Cu}$ in aquatic ecosystems is important because these ions can have severe effects on human health and the environment. Gold ( $\mathrm{Au}$ ) nanomaterials are attractive sensing materials because of their unique size- and shape-dependent optical properties. This review focuses on optical assays for $\mathrm{Hg}, \mathrm{Pb}$, and $\mathrm{Cu}$ ions using functionalized Au nanomaterials. The syntheses of functionalized Au nanomaterials are discussed (Lin et al. 2011).

In the present investigation, the author successfully synthesized and applied AuNPs capped with 2-mercapto succinic acid (MSA) for mercury species determination present in various environmental samples up to nanolevels without any interference.

\section{Experimental section}

\section{Chemicals}

All the chemicals and solvents used were of analytical reagent grade and procured from Sigma-Aldrich Company and double-distilled water was used to prepare all solutions in the experiments. Gold chloride $\left(\mathrm{HAuCl}_{4} \cdot 3 \mathrm{H}_{2} \mathrm{O}\right)$ was purchased from Research Lab fine chem. Industries, India Limited. Analytical grade trisodium citrate, 2-MSA, sodium chloride $(\mathrm{NaCl})$ and other chemicals were purchased from Sigma-Aldrich Company. Double-distilled water was used throughout the experiment.

\section{Instrumentation}

A pH meter (Elico, Model LI-129, India) with combined glass electrode was used for $\mathrm{pH}$ measurements. A single pan analytical balance (Dhona, Model 100 DS, India) was employed for weighing the samples. A Systronics UV-Vis spectrophotometer 118 model with 1-cm-matched quartz cells was used for all absorbance measurements. Scanning electron microscope (SEM) image was taken using a FEI QUANTA-200 SEM instrument. High-resolution transmission electron microscopy (HRTEM) was carried out 
using a 300-kV JEOL-3011 instrument with an ultrahighresolution (UHR) pole piece.

Synthesis of gold nanoparticles

Gold nanoparticles were synthesized by citrate reduction of gold chloride $\left(\mathrm{HAuCl}_{4} \cdot 3 \mathrm{H}_{2} \mathrm{O}\right)$ solution mixed with trisodium citrate following Turkevich method. $5 \mathrm{~mL}$ of $1 \mathrm{M}$ $\mathrm{HAuCl}_{4} \cdot 3 \mathrm{H}_{2} \mathrm{O}$ was diluted with $90 \mathrm{~mL}$ of double-distilled water and heated until it begins to boil. To this, was added $5 \mathrm{~mL}$ of $1 \mathrm{M}$ trisodium citrate solution and the reaction continued until the solution turned wine red. Later the surface of the AuNPs was modified under stirring at $50{ }^{\circ} \mathrm{C}$ for $10 \mathrm{~h}$ by mixing with excess of 2-MSA and the structure was determined using SEM. The thiol was introduced as its sodium salt by stoichiometrical neutralization with sodium hydroxide. The resulting suspension had a conductivity of $580 \pm 20 \mu \mathrm{S} / \mathrm{cm}$, and an initial $\mathrm{pH}$ of $6.5 \pm 0.3$.

Stability of gold nanoparticles

A bivalent citrate anion and a bivalent MSA anion will contribute equally to the conductivity, the same value of conductivity implies that the total concentration of anions (from citrate and MSA, as well as $\mathrm{Cl}^{-}$released from $\mathrm{AuCl}_{4}$ during reduction and $\left.\mathrm{OH}^{-}\right)$and counter ions $\left(\mathrm{Na}^{+}, \mathrm{H}^{+}\right)$ would be roughly the same, although the relative concentration of each species is slightly different between the modified and unmodified samples. This means there is no significant difference in the outer ionic atmosphere of the electric double layer of the modified and unmodified particles in the $\mathrm{pH}$ range from 5.3 to lower values upon $\mathrm{HCl}$ addition.

Synthesis of alumina-supported MSA-capped gold nanoparticles

$5 \mathrm{~g}$ of neutral-activated alumina was soaked in $15 \mathrm{ml}$ of MSA-capped AuNPs suspension for $30 \mathrm{~min}$. Once the solution became colorless, it was replaced with another fresh 15-ml MSA-capped AuNPs solution. This procedure was repeated until there was no color change for the supernatant. After decanting the supernatant, MSA-capped gold nanoparticle-coated alumina was washed thoroughly with distilled water and dried under ambient condition.

Preparation of mercury solution

Mercury stock solution was prepared using mercuric chloride which is procured from Merck Company, Mumbai. Standard mercury solutions were prepared with different concentrations to evaluate the reagent efficiency toward the real sample analysis. $2 \mathrm{ml}$ of $1.0 \mathrm{mg} / \mathrm{l}$ mercury solution was spiked to the real samples for monitoring the mercury species in environmental water, vegetable and crop samples which are collected near selected industrial areas.

Determination of mercury using alumina-supported MSA-capped gold nanoparticles

The interaction between alumina-supported MSA-capped AuNPs and $\mathrm{Hg}$ (II) ions was studied using a column setup. The column is filled with $1 \mathrm{~g}$ of MSA-capped AuNPscoated alumina and to this $1.0 \mathrm{mg} / \mathrm{L} \mathrm{Hg}$ (II) solution was passed at a flow rate of $6 \mathrm{~mL} / \mathrm{min} .6 \mathrm{~mL}$ of the treated water was collected at an interval of $100 \mathrm{~mL}$ and analyzed for residual mercury using UV-Vis spectrophotometry. The experiment was continued till mercury was detected in the treated sample.

For studying the interaction of supported AuNPs with $\mathrm{Hg}(0), 1.0 \mathrm{mg} / \mathrm{L} \mathrm{Hg}(\mathrm{II})$ was reduced with dilute aqueous $\mathrm{NaBH}_{4}$ (ten times the mercury concentration) and allowed to stand for $1 \mathrm{~h}$. Afterward the solution was passed through a column containing $1 \mathrm{~g}$ of MSA-capped AuNPs-coated alumina. $6 \mathrm{ml}$ of the treated water was collected at an interval of $100 \mathrm{~mL}$. Before analysis, the sample collected was treated with concentrated $\mathrm{HCl}$ for the oxidation of $\mathrm{Hg}$. The experiment was continued till mercury was detected in the sample. Same experiment was repeated with $1.0 \mathrm{mg} / \mathrm{L}$ $\mathrm{Hg}(\mathrm{II})$ also. To find the interaction of $\mathrm{Hg}(0)$ with alumina, the experiment was repeated with $1 \mathrm{~g}$ of alumina in absence of MSA-capped AuNPs.

Batch experiments were done for finding the interaction of $1 \mathrm{~g}$ of MSA-capped AuNPs-coated alumina with mercury. For the study, $1 \mathrm{~g}$ of MSA-capped AuNPs-coated alumina was transferred to $\mathrm{NaBH}_{4}$ and treated with $250 \mathrm{~mL}$ of $0.75 \mathrm{mg} / \mathrm{L} \mathrm{Hg}(\mathrm{II})$ and stirred continuously.

\section{SEM and TEM analysis}

Structural and morphological changes of AuNPs capped with MSA were done using SEM and HRTEM and shown in Fig. 1a and $b$.

\section{Detection and removal of boron}

$10 \mathrm{~mL}$ of the sample was collected from the column outlet and analyzed for boron by a simple procedure proposed by Pradeep et al. To have a large boron concentration in the treated water, a column study was done with $2.0 \mathrm{mg} / \mathrm{L}$ $\mathrm{Hg}$ (II) reduced with 20 times $\mathrm{NaBH}_{4}$. Performance of magnesium oxide as a boron adsorbent was tested. $250 \mathrm{mg}$ of magnesium oxide was transferred to $50 \mathrm{~mL}$ of the polluted water and stirred continuously. The samples collected 

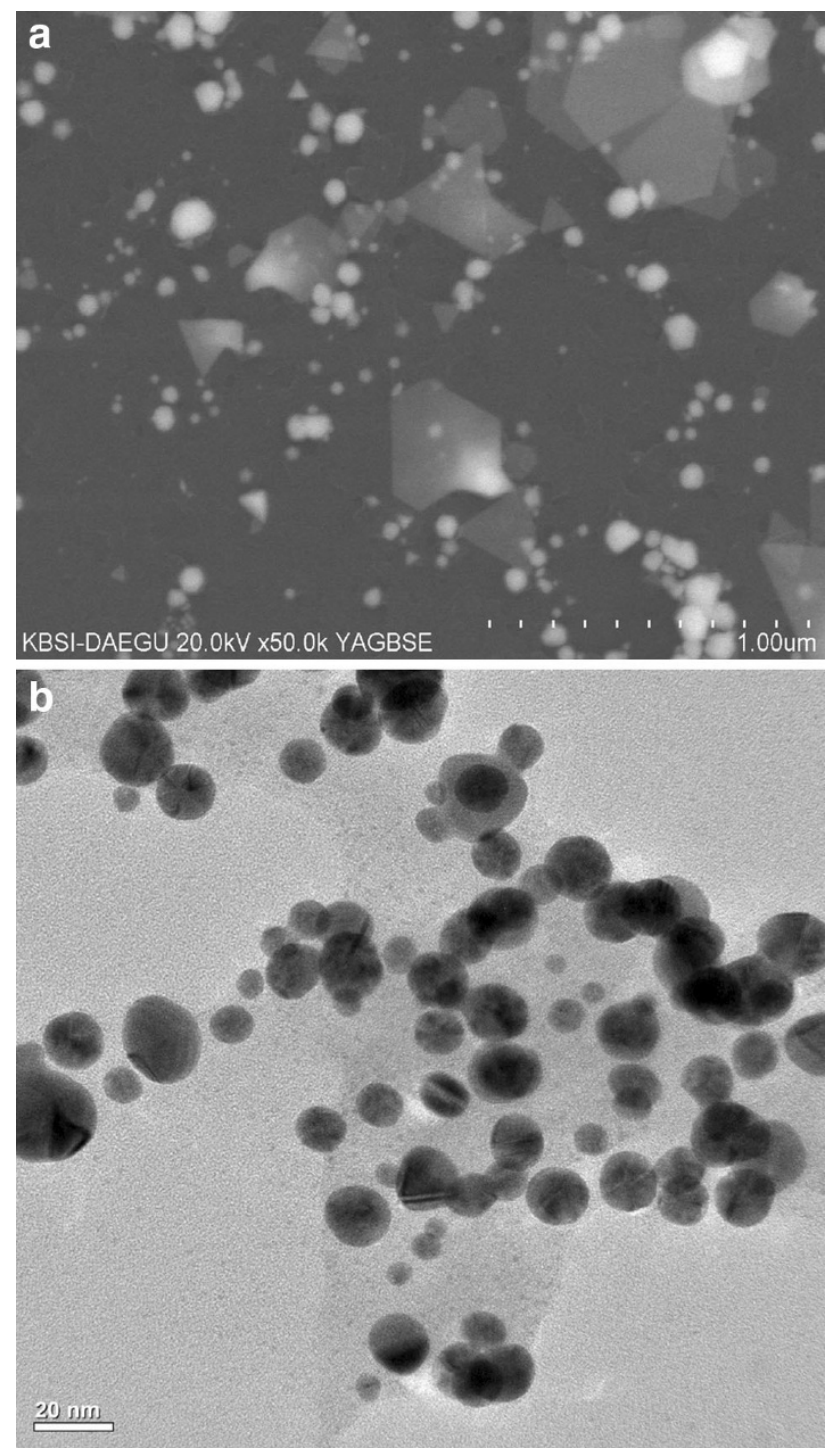

Fig. 1 a SEM images for gold nanoparticles. b TEM images for gold nanoparticles

at different time intervals were centrifuged and the supernatant was analyzed for boron.

\section{Results and discussion}

The formation of the synthesized AuNPs has been known in the solution by the color changing from pale yellow to wine red. The color change can be easily identified by the naked eye. It clearly indicates that citrate ions act as stabilizing agent, capping agent and also they act as reducing agent to convert $\mathrm{Au}^{+3}$ to $\mathrm{Au}^{0}$. In addition, AuNPs have a characteristic surface plasma resonance band around $300-800 \mathrm{~nm}$ and the maximum absorbance was found at $547 \mathrm{~nm}$ which is shown in Fig. 2. Temperature also plays

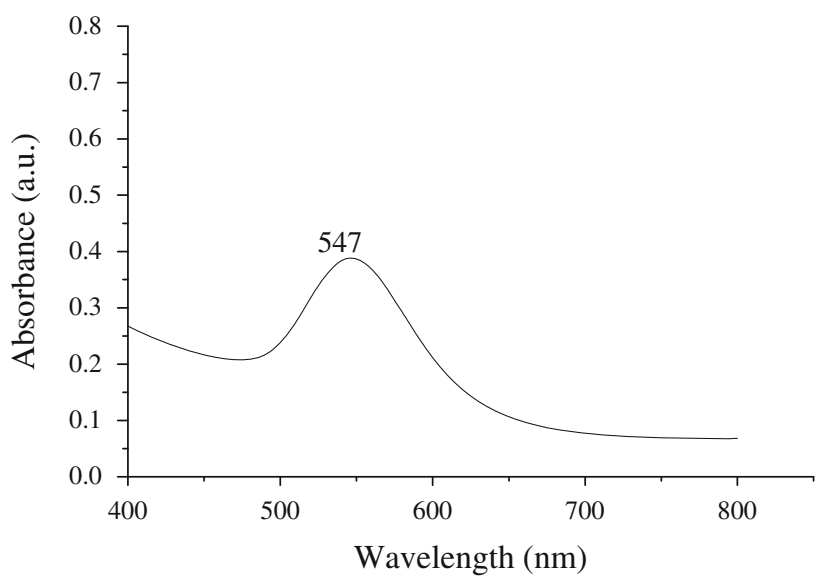

Fig. 2 Shows UV-visible spectra of gold nanoparticles

an important role in reaction mechanism and $50{ }^{\circ} \mathrm{C}$ shows maximum absorbance under controlled conditions.

Stability

Citrate and MSA ions having negative charges maintain stability in AuNPs solution. Adding of different concentrations of $\mathrm{NaCl}$ solution to that of AuNPs increases stability for AuNPs and it was clearly observed in UV-Visible spectrophotometry. The domino effect confirms that maximum stability for AuNPs was obtained at $10 \mathrm{M} \mathrm{NaCl}$ concentration.

Column loaded with $1 \mathrm{~g}$ of MSA-capped gold nanoparticle-coated alumina

The column used was $1.5 \mathrm{~cm}$ in diameter and $30 \mathrm{~cm}$ in height. The adsorbent was packed in the column and the flow rate through the column was maintained constantly. The loading of $\mathrm{Hg}$ (II) on $2 \mathrm{~g}$ of MSA-capped AuNPscoated alumina is $100 \mathrm{mg} / \mathrm{kg}$, in terms of gold it is $200 \mathrm{mg}$ of $\mathrm{Hg}(\mathrm{II})$ per $738 \mathrm{mg}$ gold. This uptake capacity is relatively low. It may be due to the poor physical interaction between gold nanoparticle and $\mathrm{Hg}$ (II) ions.

To improve the mercury uptake by supported nanoparticles, we studied the interaction of $\mathrm{Hg}(0)$ with AuNPs after reducing $\mathrm{Hg}$ (II) with $\mathrm{NaBH}_{4}$. The extremely high-uptake capacity of gold nanoparticle surface may be due to the gold mercury amalgam and the formation of amorphous mercury layer over gold nanoparticle surface.

Detection of mercury

Under optimum conditions, synthesised MSA-capped AuNPs were used successfully for the determination of mercury in various soil and water samples. MSA-capped AuNPs mixed with different concentrations of mercury 


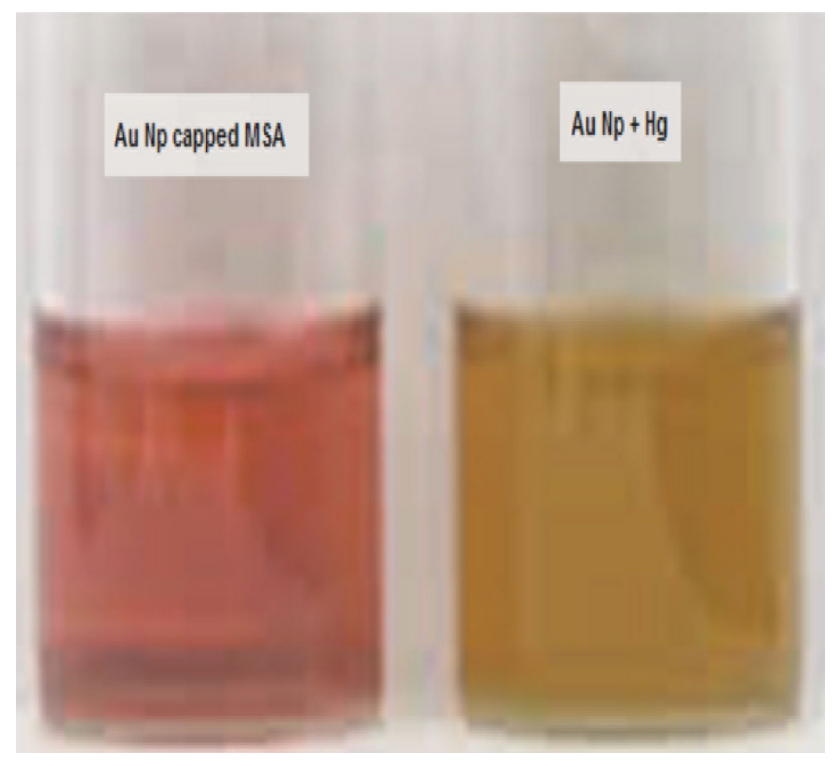

Fig. 3 Shows MSA-capped AuNPs and MSA-capped AuNPs with mercury

Table 1 Determination of mercury in water samples

\begin{tabular}{lllrll}
\hline S.No. & Origin of Sample & \multicolumn{4}{l}{ Mercury ion found $\left(\mu \mathrm{g} \mathrm{L}^{-1}\right)^{\mathrm{a}}$} \\
\cline { 3 - 6 } & & $\mathrm{I}$ & \multicolumn{1}{c}{$\mathrm{II}$} & $\mathrm{III}$ & $\mathrm{IV}$ \\
\hline 1. & Tap water & 14.40 & 3.76 & 10.23 & $\mathrm{BDL}$ \\
2. & Well water & 12.72 & 9.95 & 12.36 & 0.23 \\
3. & Boring water & 16.83 & 10.69 & 16.18 & 1.62 \\
4. & Irrigation water & 11.86 & 8.44 & 13.24 & $\mathrm{BDL}$ \\
\hline
\end{tabular}

I: Amara raja batteries Industry, II: Lanco Cement Industry, III: Avanthi Leather Industry, IV: Heritage Dairy Industry

$B D L$ below detection limit

a Average of six determinations

show no color due to the absence of $\mathrm{NaCl}$ solution and presence of negative ions which act as stabilizer. By the addition of $10-\mathrm{M} \mathrm{NaCl}$ solution to the mixture, the color was changed from wine red to orange-yellow as shown in Fig. 3. The appearance of orange-yellow color indicates that MSA-capped AuNPs having negative ions hold mercury ions in presence of $\mathrm{NaCl}$. After $10 \mathrm{~min}$, the color slowly turns to yellow due to mercury concentration. MSA ions act as reducing agent to synthesize AuNPs from gold chloride $\left(\mathrm{HAuCl}_{4}\right)$, which is wine red in color. Trisodium citrate along with MSA contains many negative ions which helps to reduce $\mathrm{Au}^{+3}$ to $\mathrm{Au}^{0}$, and it also because of high negative charges of citrate also acts as stabilizer and maintain wine red color for AuNPs even mercury solution has been added. Whenever $\mathrm{NaCl}$ solution was added, then the AuNPs' solution changed its color from wine red to orange-yellow depending on mercury solution concentration.
Table 2 Determination of mercury in vegetables and crop samples

\begin{tabular}{llllll}
\hline S.No. & Origin of sample & \multicolumn{4}{c}{ Mercury ion found $\left(\mu \mathrm{g} \mathrm{L}^{-1}\right)^{\mathrm{a}}$} \\
\cline { 3 - 6 } & & $\mathrm{I}$ & $\mathrm{II}$ & $\mathrm{III}$ & $\mathrm{IV}$ \\
\hline 1. & Brinjal & 6.43 & 1.42 & 5.53 & - \\
2. & Drum stick & 3.68 & 2.80 & 6.48 & $\mathrm{BDL}$ \\
3. & Ladyfinger & 4.36 & 0.64 & 4.21 & $\mathrm{BDL}$ \\
4. & Paddy & 8.92 & 4.68 & 9.90 & 0.63 \\
5. & Ground nut & 9.96 & 3.26 & 10.32 & 1.42 \\
\hline
\end{tabular}

I: Amara raja batteries Industry, II: Lanco Cement Industry, III: Avanthi Leather Industry, IV: Heritage Dairy Industry

$B D L$ below detection limit

${ }^{\text {a }}$ Average of six determinations

Table 3 Comparision of mercury in various water samples

\begin{tabular}{|c|c|c|c|c|c|}
\hline S.No & $\begin{array}{l}\text { Name of the } \\
\text { industry }\end{array}$ & $\begin{array}{l}\text { Sample } \\
\text { area }\end{array}$ & $\begin{array}{l}\text { Standard } \\
\text { method }\end{array}$ & $\begin{array}{l}\text { Present } \\
\text { method }\end{array}$ & C.V. \\
\hline \multirow[t]{4}{*}{1} & \multirow{4}{*}{$\begin{array}{c}\text { Amara Raja } \\
\text { Batteries }\end{array}$} & Sample $\mathrm{I}^{1}$ & 1.0 & $0.98 \pm 0.02$ & 2.04 \\
\hline & & Sample II ${ }^{2}$ & 0.95 & $0.92 \pm 0.04$ & 4.34 \\
\hline & & Sample III ${ }^{3}$ & 0.90 & $0.88 \pm 0.02$ & 2.28 \\
\hline & & Sample IV ${ }^{4}$ & 0.90 & $0.90 \pm 0.06$ & 6.66 \\
\hline \multirow[t]{4}{*}{2} & \multirow{4}{*}{$\begin{array}{l}\text { Lanco Cement } \\
\text { Industry }\end{array}$} & Sample $I^{5}$ & 0.90 & $0.88 \pm 0.04$ & 4.54 \\
\hline & & Sample II ${ }^{6}$ & 0.75 & $0.72 \pm 0.02$ & 2.78 \\
\hline & & Sample III $^{7}$ & 0.80 & $0.76 \pm 0.01$ & 1.32 \\
\hline & & Sample IV ${ }^{8}$ & 0.75 & $0.68 \pm 0.02$ & 2.24 \\
\hline \multirow[t]{4}{*}{3} & \multirow{4}{*}{$\begin{array}{l}\text { Avanthi Leather } \\
\text { Industry }\end{array}$} & Sample $\mathrm{I}^{9}$ & 0.98 & $0.95 \pm 0.04$ & 4.20 \\
\hline & & Sample II $^{10}$ & 0.92 & $0.90 \pm 0.02$ & 2.22 \\
\hline & & Sample III ${ }^{11}$ & 0.90 & $0.86 \pm 0.06$ & 6.98 \\
\hline & & Sample IV ${ }^{12}$ & 0.90 & $0.89 \pm 0.02$ & 2.24 \\
\hline \multirow[t]{4}{*}{4} & \multirow{4}{*}{$\begin{array}{l}\text { Heritage Food } \\
\text { India }\end{array}$} & Sample $I^{13}$ & 0.88 & $0.86 \pm 0.02$ & 2.32 \\
\hline & & Sample II $^{14}$ & 0.75 & $0.74 \pm 0.02$ & 2.70 \\
\hline & & Sample III ${ }^{15}$ & 0.66 & $0.62 \pm 0.02$ & 3.22 \\
\hline & & Sample IV ${ }^{16}$ & 0.70 & $0.68 \pm 0.02$ & 2.94 \\
\hline
\end{tabular}

Sample 1: Karakambadi rural village, sample 2: Dodhla mitta village, sample 3: Karakambadi village, sample 4: Mangalam village, sample 5: Rachagunnari village, sample 6: Marrimakula Chenu Kandriga village, sample 7: Maddiledu village, sample 8: Kapugunneri village, sample 9: Kallivettu village, sample 10: Telugu Ganga reservoir, sample 11: Oneness University campus, sample 12: Thondambattu village, sample13: Diguva Kasipentla village, sample 14: Chigrapalli village, sample 15: Bodumbai village, sample 16: Eguva Kasipentla village

Analysis of water samples

Gold nanoparticles complexation with mercury solution in presence of $\mathrm{NaCl}$ was studied using real water samples. These samples were collected from industrial areas, i.e., Amara Raja Batteries, Lanco pvt ltd, Avanthi Leather Industry, Heritage Dairy, Andhra Pradesh, India. These samples were spiked with the mercury and Spectrophotometric determination was done using $1 \mathrm{ng} / \mathrm{mL}$ and the results are shown in Tables 1, 2, 3 . 


\section{Conclusion}

Gold nanoparticles capped with MSA were successfully applied for the determination of mercury in various environmental water and vegetable samples up to ppb levels. This method is sensitive and selective for mercury determination in water and vegetable samples in presence of AuNPs. The developed method is used safely for the determination of mercury in various environmental samples.

Acknowledgments The author thanks to Umesh Kumar SharmaScientist-D, Department of Science and Technology, who supports me to sanctioned project with reference number SR/FTP/ES-125 under fast track young scientist scheme to work continuously on gold nanoparticles.

Open Access This article is distributed under the terms of the Creative Commons Attribution License which permits any use, distribution, and reproduction in any medium, provided the original author(s) and the source are credited.

\section{References}

Fu X, Chen L, Li J (2012) Ultrasensitive colorimetric detection of heparin based on self-assembly of gold nanoparticles on graphene oxide. Analyst 137(16):3653-3658. doi:10.1039/ c2an35552c

Giannoulis KM, Giokas DL, Tsogas GZ, Vlessidis AG (2014) Ligand- free gold nanoparticles as colorimetric probes for the non destructive determination of total dithiocarbamate pesticides after solid phase extraction. Talanta 119:276-283. doi:10.1016/j. talanta.2013.10.063

Knecht MR, Sethi M (2009) Bio-inspired colorimetric detection of $\mathrm{Hg}^{2+}$ and $\mathrm{Pb}^{2+}$ heavy metal ions using $\mathrm{Au}$ nanoparticles. Anal Bioanal Chem 394(1):33-46. doi:10.1007/s00216-008-2594-7

Krishna MV, Chandrasekaran K, Karunasagar D (2010) On-line speciation of inorganic and methyl mercury in waters and fish tissues using polyaniline micro-column and flow injectionchemical vapour generation-inductively coupled plasma mass spectrometry (FI-CVG-ICPMS). Talanta 81(1-2):462-472. doi:10.1016/j.talanta.2009.12.024

Leopold K, Zierhut A, Huber J (2012) Ultra-trace determination of mercury in river waters after online UV digestion of humic matter. Anal Bioanal Chem 403(8):2419-2428. doi:10.1007/ s00216-012-5851-8

Li H, Guo J, Ping H, Liu L, Zhang M, Guan F, Sun C, Zhang Q (2011) Visual detection of organophosphorus pesticides represented by mathamidophos using $\mathrm{Au}$ nanoparticles as colorimetric probe. Talanta 87:93-99. doi:10.1016/j.talanta.2011.09.046

Li L, Leopold K, Schuster M (2013) Comparative study of alkylthiols and alkylamines for the phase transfer of gold nanoparticles from an aqueous phase to $\mathrm{n}$-hexane. $\mathrm{J}$ Colloid Interface Sci 397:199-205. doi:10.1016/j.jcis.2013.01.062

Lin CY, Yu CJ, Lin YH, Tseng WL (2010) Colorimetric sensing of silver(I) and mercury(II) ions based on an assembly of Tween 20-stabilized gold nanoparticles. Anal Chem 82(16):6830-6837. doi:10.1021/ac1007909

Lin YW, Huang CC, Chang HT (2011) Gold nanoparticle probes for the detection of mercury, lead and copper ions. Analyst 136(5):863-871. doi:10.1039/c0an00652a

Lou T, Chen Z, Wang Y, Chen L (2011) Blue-to-red colorimetric sensing strategy for $\mathrm{Hg}^{2+}$ and $\mathrm{Ag}^{+}$via redox-regulated surface chemistry of gold nanoparticles. ACS Appl Mater Interfaces 3(5):1568-1573. doi:10.1021/am200130e

Panichev N, Kalumba MM, Mandiwana KL (2014) Solid phase extraction of trace amount of mercury from natural waters on silver and gold nanoparticles. Anal Chim Acta 813:56-62. doi:10.1016/j.aca.2014.01.011

Sun L, Zhang C, Chen L, Liu J, Jin H, Xu H, Ding L (2009) Preparation of alumina-coated magnetite nanoparticle for extraction of trimethoprim from environmental water samples based on mixed hemimicelles solid-phase extraction. Anal Chim Acta 638(2):162-168. doi:10.1016/j.aca.2009.02.039

Yordanova T, Vasileva P, Karadjova I, Nihtianova D (2014) Submicron silica spheres decorated with silver nanoparticles as a new effective sorbent for inorganic mercury in surface waters. Analyst 139(6):1532-1540. doi:10.1039/c3an01279d

Zhang H, Liu Q, Wang T, Yun Z, Li G, Liu J, Jiang G (2013) Facile preparation of glutathione-stabilized gold nanoclusters for selective determination of chromium (III) and chromium (VI) in environmental water samples. Anal Chim Acta 770:140-146. doi:10.1016/j.aca.2013.01.042

Zhao L, Jin Y, Yan Z, Liu Y, Zhu H (2012) Novel highly selective detection of $\mathrm{Cr}(\mathrm{III})$ in aqueous solution based on a gold nanoparticles colorimetric assay and its application for determining Cr(VI). Anal Chim Acta 731:75-81. doi:10.1016/j.aca. 2012.04.022

Zierhut A, Leopold K, Harwardt L, Schuster M (2010) Analysis of total dissolved mercury in waters after on-line preconcentration on an active gold column. Talanta 81(4-5):1529-1535. doi:10. 1016/j.talanta.2010.02.064 